ISSN: 2238-8052

\title{
ESTUDO AMBIENTAL DA MICROBACIA DO RIACHO DO MEL EM GRAVATÁ (PE): PROCESSO DE USO E OCUPAÇÃO DA TERRA NO CONTEXTO DO BAIRRO RIACHO DO MEL
}

\author{
ENVIRONMENTAL STUDY OF THE RIACHO DO MEL WATERSHED IN GRAVATÁ (PE): PROCESS \\ OF THE LAND USE AND OCCUPATION IN THE RIACHO DO MEL DISTRICT CONTEXT
}

Armando Peres QUINTAS NETO 1

Artigo recebido em 05/07/2017 e aceito em 29/11/2017

\begin{abstract}
Palavras-chave:
Bacia hidrográfica

Diagnóstico

ambiental

Impactos urbanos

0 presente artigo propõe fazer um estudo ambiental acerca do uso e da pressão antrópica na microbacia do riacho do $\mathrm{Mel}$, em face da expansão da área urbana no município de Gravatá-PE. Tendo em vista o desinteresse pelo ambiente demonstrado por cidades de pequeno porte no Nordeste brasileiro, buscamos fazer um levantamento de aspectos geológicos, geomorfológicos, climáticos e de uso do solo, bem como destacar a visão dos moradores da área sobre o riacho. 0 material cartográfico representa um quadro de considerável de degradação e consequente alteração das características da área onde a ocupação humana se adensa.
\end{abstract}

\section{R E S U M O}

Keywords:

Watershed Environmental diagnosis Urban impacts

\begin{abstract}
A B S T R A C T
This article propose an environmental study on the anthropic use and pressure in the Riacho do Mel watershed, due to the expansion of the urban area in the city of Gravatá$\mathrm{PE}$, Brazil. Considering the environmental disinterest shown in the cities small in Brazilian northeast, we sought to collect data about geological, geomorphological, climatic aspects and the soil use, as well as to investigate the point of view of the nearby residents about the creek. The cartographic production represents a considerable degradation and consequent alteration of the area characteristics where the human occupation increases.
\end{abstract}

\section{INTRODUÇÃO}

A ocupação "desordenada" é uma realidade de muitas cidades brasileiras nos seus espaços intra e periurbanos provocando alterações constantes de suas condições ambientais. Tais mudanças geralmente fragilizam áreas como as de nascentes de rios, topo de morros, matas ciliares e outros ecossistemas vulneráveis. Nessa perspectiva, o desenvolvimento de estudos que visem garantir o equilíbrio ambiental dessas áreas torna-se fundamental para, pelo menos, mitigar possíveis impactos (CUNHA, 2010).

O planejamento ambiental, nesse sentido, busca apresentar os possíveis impactos que podem ser causados em uma determinada área durante a realização e o efetivo uso de empreendimentos 
imobiliários. Deve-se levar em consideração, contudo, a advertência de Sánchez (2013) para o fato de não se incorrer no vezo de se considerar impacto como sendo unicamente as consequências negativas ao ambiente. Deve-se entender que as ações humanas sempre causam uma reorganização espacial considerável e que essa reorganização, pode causar variações nas condições de vida de um conjunto das espécies biológicas que compõem o ambiente, dentre as quais, os seres humanos. Devemos assim ponderar os prós e os contras das ações, admitindo para tanto, um nível máximo de variação que não pode ser ultrapassado sob a pena de colocar em risco as caraterísticas fundamentais do ambiente.

Sabe-se ainda, que a elaboração de estudos de impacto ambiental no desenvolvimento de empreendimentos em cidades brasileiras, é comumente alijada do processo planejador. Quando são desenvolvidos, tais estudos por vezes apresentam abordagens superficiais sobre desenvolvimento racional e preservação efetiva de ambientes com alta fragilidade biológica. Paralelamente a esse fato, considera-se inadmissível que o crescimento urbano brasileiro apresente-se impulsionado majoritariamente pela especulação imobiliária, em detrimento de condições efetivas de oferta de qualidade de vida.

A bacia hidrográfica, nesse contexto, tem se tornado uma escala fundamental de análise e de estruturação do planejamento ambiental. Braga (2009), ao abordar a lei federal $n^{\circ} 9.433$, aponta que o reconhecimento da bacia hidrográfica como unidade básica da gestão de recursos hídricos, além de elencar os principais pontos a serem considerados num plano de manejo, traz como principal preocupação as modificações inerentes ao crescimento demográfico e as mudanças no uso do solo, a disponibilidade em quantidade e qualidade dos recursos hídricos, bem como conflitos potenciais.

0 presente estudo busca, através do estudo ambiental de parte da microbacia do Riacho do Mel em Gravatá - PE, analisar suas dinâmicas em face da iminente ocupação, dado o desenvolvimento de um grande empreendimento imobiliário do bairro Riacho do Mel, o qual está ocasionando uma progressiva expansão urbana na área.

Para atender esse objetivo, elaborou-se uma base cartográfica cruzando as informações aferidas através da ferramenta de geoprocessamento com os dados levantados em campo, suscitando um quadro atual da área em questão e contribuindo para o futuro da organização urbana da cidade, bem como para a elaboração de uma base de dados para outros estudos.

Buscamos observar a microbacia em questão, através da esfera da teoria geral dos sistemas que, conforme Vasconcellos (2009), compreende a noção de sistema e, perpassando a esfera do método, traz o pensamento sistêmico como um paradigma científico emergente. A autora esclarece que tal teoria nos permite assimilar o objeto em questão, seja natural ou artificial, a partir da rede de relações e influências exercidas entre os elementos que o compõem e/ou com outros sistemas, sem deixar de considerar o observador nesta teia. Sabendo-se que uma microbacia é um sistema aberto, a

1 Graduação em Geografia pela Universidade Federal de Pernambuco - UFPE. E-mail: armando-peres@hotmail.com. 
evolução do quadro de preservação ou degradação, dependerá fortemente do tipo de relação que ali se estabelecera. Assim, entendendo o empreendimento imobiliário como um input no sistema da microbacia, buscou-se esclarecer os outputs que dele decorrerão.

\section{A MICROBACIA DO RIACHO DO MEL}

\subsection{Características ambientais}

A área do estudo localiza-se na Mesorregião do Agreste Central e Microrregião do Vale do Ipojuca, na cidade de Gravatá - PE, que dista $87 \mathrm{~km}$ do Recife e tem pouco mais de $506 \mathrm{~km}^{2}$. Ocupa $0,8 \%$ do estado de Pernambuco e tem como ponto referencial, as coordenadas $8^{\circ} 12^{\prime} 16^{\prime \prime}$ de latitude sul e $35^{\circ} 35^{\prime} 10^{\prime \prime}$ de longitude oeste de Greenwich. 0 acesso à cidade, tendo como partida a capital do estado, se dá pela BR-232 - Rodovia Luiz Gonzaga.

A microbacia do Riacho do Mel encontra-se ao sul do centro urbano, podendo ser acessada pela primeira perimetral urbana vindo da BR-232. Esta segue até a estrada Gravatá-Mandacaru (PE-87) que atualmente se encontra em processo de asfaltamento e ampliação, margeando o loteamento, com cerca de $26 \mathrm{~km}^{2}$. O Riacho do Mel sendo, segundo estudo realizado pelo órgão estadual CPRH, é um dos principais tributários pela margem direita da Bacia do Ipojuca².

Sua vertente principal se encontra na margem direita, a aproximadamente 600 metros de altitude e se origina da união de dois fluxos, o mais ao sul, verte do rancho Vale Verde e o mais a leste, da Fazenda Camaçari. Durante boa parte do ano, sua dinâmica é intermitente e nos períodos secos chega ao nível freático em sua jusante, ficando com baixíssimo fluxo estacionário à montante. 0 que também é resultado de alguns barramentos feitos a poucos metros antes de desaguar no rio Ipojuca.

0 clima na região é ameno de classificação AS, frio e seco, que varia entre $25^{\circ}$ e $30^{\circ}$ no verão e $18^{\circ}$ e $24^{\circ}$ no inverno, seu regime pluviométrico é caracterizado por chuvas de outono-inverno com uma média anual de 583,69 mm, espaçadas desde o fim do mês de março até agosto.

Geomorfologicamente, a microbacia faz parte da porção oriental do Planalto da Borborema, o que confere topografia irregular com morros de até 800 metros de altitude no entorno da microbacia, tendendo em suas bordas a um grau de declividade fortemente ondulado (20 - 45\%) como é o caso da vertente à esquerda do corpo do riacho onde se localiza o empreendimento, com consequente suavização ao nível de base no corpo d'água.

\footnotetext{
2 Disponível em: http://www.cprh.pe.gov.br/downloads/05bac-ipo-res-tap.pdf acesso em: 17/08/2013 às 21:20.
} 
Para a identificação e classificação dos tipos de solo presentes na área, utilizou-se o artigo de Jacomine (2008-2009) e o mapa de solos do $\mathrm{ZAPE}^{3}$ como principais fontes de subsídios. Baseando-se na nova classificação brasileira de solos, enquadram-se os seguintes tipos: Planossolos, Neossolos, Argissolos e Latossolos, que serão definidos e situados a seguir.

As cimeiras de onde vertem os fluxos originários encontram-se em uma área de Latossolos, definidos como solos de avançado estágio de intemperização, bastante evoluídos, como resultado de enérgicas transformações do material constituído, apresentando horizonte B latossólico, imediatamente abaixo de qualquer um dos tipos de horizonte superficial, com exceção do hístico.

Em sua confluência cortam uma área onde predominam os Argissolos, nome que faz referência ao horizonte B textural onde há presença de argila de atividade baixa ou alta conjugada com saturação por bases baixa ou caráter alético.

Pouco antes da união destes fluxos para formar o corpo do Riacho do Mel até sua desembocadura no rio Ipojuca, predominarão os Planossolos, de maior expressão na microbacia. Caracterizam-se por serem imperfeitamente ou mal drenados, com horizonte superficial ou subsuperficial de origem eluvial de textura mais leve. Apresentando uma diferença acentuada na transição do horizonte A para o B, subjacente e adensado, apresenta alta concentração de argila e é de permeabilidade lenta ou muito lenta.

Na borda situada ao norte, oposta à nascente, há presença de um relevo de altitude elevada, correspondente ao divisor de águas desta porção da microbacia totalmente composto por Neossolos, material onde houve pouca atuação da pedogênese, levando a ter seu horizonte B característico de pouca expressão com maior compleição para o material de origem.

As unidades de relevo anteriormente citadas são esparsamente recobertas quase que predominantemente pela caatinga hipoxerófila.

\begin{abstract}
Na caatinga pode ser encontradas desde áreas de vegetação arbustiva baixa e rala até florestas com indivíduos que atingem facilmente $8 \mathrm{~m}$ de altura, sendo caracterizada por espécies micrófilas e decíduas, além espinhos, acúleos, folhas e caules suculentos, e o predomínio de ervas anuais. Estas características visam proteger a planta contra a perda d'água por transpiração causada pelo forte calor, possibilitando as mesmas sobreviverem em ambientes com elevado deficit hídrico, como o semiárido nordestino. (Zappi, 2008, p.35).
\end{abstract}

Os diferentes tipos de uso da terra ditaram a eliminação da cobertura vegetal, de modo que é perceptível, através da observação deste fato, a transição entre a paisagem rural e a urbana, gradualmente ocorrendo.

\footnotetext{
3 Zoneamento Agroecológico de Pernambuco, disponível em: http://www.uep.cnps.embrapa.br/zape/cartas/Caruaru.pdf acesso em: 21/08/2013 às 02:33
} 
O conjunto dessas características ambientais influi na ocupação da área, na medida em que configuram um dos principais atrativos do município, o clima ameno e sua paisagem rural. Tornando assim, os espaços periurbanos, os primeiros buscados para empreendimentos imobiliários.

\subsection{0 bairro Riacho do Mel}

Ao falarmos sobre a categoria bairro estamos evocando o espaço vivido, onde se dá o cotidiano e as relações sociais que tendem a ser mais próximas e imediatas. Estas características fazem referência à noção de lugar, que ocupa nos estudos urbanos, uma posição de destaque devido à escala em que os fenômenos são observados. Buscou-se nas palavras de Carlos (2007, p.18), o embasamento teórico sobre a relação entre os bairros e a produção do espaço intraurbano, destacando que "São os lugares que o homem habita dentro da cidade que dizem respeito a seu cotidiano e a seu modo de vida onde se locomove, trabalha, passeia, flana, isto é pelas formas através das quais o homem se apropria e que vão ganhando o significado dado pelo uso".

Impulsionada pela aptidão turística, voltada para o lazer (habitações de segunda-residência, hotéis fazenda, chácaras), o município de Gravatá vive desde o início da década passada o momento de maior aquecimento do seu mercado imobiliário, fato antes perceptível nas épocas de alta estação para o turismo local, de junho a agosto, ocorrendo com uma frequência de tempo mais curta, como destaca o fragmento do trabalho de Viana Rodrigues (2007, p.78): “Nos finais de semana o município chega a receber por volta de 50.000 pessoas entre moradores de segunda-residência e turista de final de semana que se hospedam em casa de amigos, ou na rede hoteleira local".

Tal demanda não poderia ser ignorada por muito tempo pelas grandes construtoras, que atuam de forma incisiva na capital e em sua região metropolitana, ditando há muito o padrão habitacional da cidade. Um grande conglomerado empresarial, com sede principal em Recife, é o responsável pelo empreendimento do Loteamento Fazenda Riacho do Mel.

0 nome se deve ao desmembramento de uma área de 50 ha feito na fazenda cortada pelo riacho. Em 2008, o loteamento se configurou da seguinte maneira: foram destinados à ocupação residencial lotes de $250 \mathrm{~m}^{2}$ e para ocupação residencial/comercial, lotes com 1,3 mil m², sendo estes últimos, localizados às margens da PE-87, em processo de pavimentação endossado pelo Governo do Estado, totalizado 866 lotes, todos já vendidos de acordo com dados da empresa responsável pelo empreendimento, divididos em 54 quadras.

No tocante à infraestrutura, o bairro se encontra atendido pela rede elétrica e de abastecimento d'água da COMPESA. A iluminação pública ainda é bastante precária, limitando-se às avenidas principais, assim como o asfaltamento das vias, presente somente nas duas principais e bastante avariadas devido ao escoamento superficial durante as chuvas. Não há linha de transporte 
público destinada diretamente ao bairro, mas o acesso por esse meio pode ser feito através de uma linha que liga o centro da cidade ao bairro vizinho ou por uma linha particular que faz o trajeto Mandacarú/Recife, através da PE-87.

Outro ponto que merece atenção refere-se à inexistência de uma rede de escoamento do esgoto sanitário no empreendimento, uma situação comum levando em conta dados obtidos no Censo $2010^{4}$ em relação ao município: dos 22.092 domicílios que possuíam banheiro, 14.213 escoavam seus dejetos pela rede geral de esgoto ou pluvial. Sabendo que parte do esgoto é escoada de forma irregular, o rio recebe uma grande porcentagem dos dejetos produzidos pela cidade, atestando assim a deficiência na infraestrutura do município.

\section{MATERIAL E MÉTODOS}

Desenvolver uma metodologia para realizar tal trabalho é, antes de tudo, uma tarefa que exige critérios para eleger os fundamentos teóricos que possam representar a realidade estudada com acurácia dentro das limitações de promovê-lo com recursos próprios. Uma dificuldade enfrentada foi que, até o fim desta pesquisa, nenhum órgão municipal ou privado, citando mais especificamente a construtora que concretizou o empreendimento, disponibilizou qualquer relatório e/ou estudo ambiental feito na área em questão, apesar de afirmar que o empreendimento está em consonância com os trâmites legais. Não ficando atestada, a exigências previstas na Lei 6.938 de 1981, que dispõe sobre a Política Nacional de Meio Ambiente (PNMA), que voltaremos a abordar em outra sessão.

A base norteadora em relação às etapas para alcançar os objetivos propostos inicialmente foi o trabalho produzido por Mendonça (1999). Porém, foi necessário promover algumas abreviações nos elementos cartográficos que constituem os produtos apresentados na sessão seguinte.

O estudo teve início em dezembro de 2012, por se tratar do ápice do período seco na região, objetivando assim captar o ciclo de vazão até a época de chuvas. Foi iniciado o registro fotográfico in loco utilizando meio de transporte próprio e câmera fotográfica. Nesta oportunidade, à guisa dos acontecimentos, travou-se conversas informais com habitantes da área, neste caso, quase que especificamente do meio rural, para aquisição de conhecimento empírico sobre o objeto de estudo.

Tais visitas foram constantes ao longo do estudo, tomando como arcabouço teórico o trabalho de Coelho (2010) para compor o recorte, considerando o caráter inicial de desenvolvimento em que se encontrava o empreendimento. A autora afirma que, "Periodizar a história da cidade implica examinar continuidades e descontinuidades/rupturas ao longo do processo de mudança, bem como os estados

\footnotetext{
${ }^{4}$ http://www.ibge.gov.br/cidadesat/xtras/temas.php?codmun=260640\&idtema=67\&search=pernambuco|gravata| censo-demografico-2010:-resultados-do-universo-caracteristicas-da-populacao-e-dos-domicilios- acesso em: 20/08/13 às 02:30.
} 
de relativa estabilidade que caracterizam cada um dos momentos identificados" (COELHO, 2010, p. 36).

E previamente à pesquisa em campo, os levantamentos de dados preexistentes, bibliográficos e de fontes secundárias, “(...) se constituem em etapas fundamentais para a caracterização geográfica da área." (MENDONÇA, 1999, p.70). Estando a área de estudo inserida na Bacia do Ipojuca, que por sua extensão e número de cidades abarcadas é de grande importância ambiental e econômica para o Estado, diversas são as instituições que produzem estudos sobre ela. Com a devida adaptação à escala de estudo, destacamos aqui a disponibilização feita pela SUDENE da carta topográfica de 1:100.000 intitulada Caruaru onde o objeto de estudo é retratado e o mapa de reconhecimento de baixa e média intensidade de solo, produzido na mesma escala usada pela EMBRAPA em seu projeto ZAPE Zoneamento Agroecológico de Pernambuco, materiais que foram bases fundamentais para o trabalho.

Ambos os autores utilizados para esta metodologia enfatizam que a inserção de um perfil socioeconômico é de fundamental importância para entender a reprodução do espaço e os consequentes impactos pelos diferentes arranjos sociais circunscritos na área, assim, Coelho (2010, p. 35) afirma "A compreensão de impactos ambientais, como processo, depende, sobretudo, de se compreender a história (não linear) de sua produção, o modelo de desenvolvimento urbano e os padrões internos de diferença social". Porém, a mesma autora avisa que o estudo fragmentado do meio biofísico natural e do meio artificial, além de classificá-los de forma separada, "Resulta também, numa distorcida, prematura e não relativizada classificação de impactos em positivos e negativos sem avaliar que o que é positivo para uma classe social pode não ser para outra ou o que é positivo num determinado momento do processo pode não ser em outro" (COELHO, 2010, P. 35).

Para explicitar as características socioeconômicas da população residente no bairro e seu entorno foi solicitado, junto à prefeitura municipal de Gravatá, dados referentes ao último censo demográfico, e também foram utilizados dados referentes às entrevistas feitas entre os anos de $2013 \mathrm{e}$ 2017, todos trabalhados em formato de planilha do software Excel. Foram entrevistados, ao todo, 411 moradores, pelo que pinçamos os seguintes dados: renda per capita da família, forma de escoamento de esgoto, coleta de lixo e se é participante ou não do programa Bolsa Família. Além desta fonte, durante as visitas de campo, as conversas travadas com moradores locais foram de grande relevância para aquisição de informações empíricas.

A última fase consistiu em demarcar pontos para georreferenciar a produção cartográfica, utilizando um aparelho de GPS, a partir da foz, até o limite da área de estudo foram marcados 22 pontos. Para o produto final, foram utilizados os softwares Terra view 4.2.2 e Google Earth, onde os dados foram trabalhados objetivando a criação de mapas de uso e ocupação da terra, hipsometria e impactos ambientais, proporcionando um recorte temporal, assegurando que as suposições que serão debatidas tenham o embasamento teórico adequado. 
A escala de tempo considerada, de dezembro de 2012 a maio de 2017, traz um caráter preventivo à pesquisa, pois, apesar de no entorno do loteamento existirem condomínios de alto padrão e empreendimentos agrícolas estabelecidos anteriormente, existem áreas que se encontram em processo de ocupação, com inúmeros lotes ainda vazios.

A inquietação inicial adveio de estudos in loco relacionados ao rio Ipojuca que corta o perímetro urbano da cidade e à situação de degradação em que este se encontra. Dentre nossos questionamentos, observar os tributários era de fundamental importância. O riacho do Mel foi escolhido devido sua iminente inserção na área urbana, donde se poderia observar desde o princípio o processo de ocupação maciça da área, tendo em vista outros usos do solo ao longo da microbacia.

Não foi encontrado nenhum levantamento específico com relação ao riacho e sua rede de drenagem, nem tão pouco das implicações que esta expansão infligirá a suas dinâmicas. Utilizou-se preliminarmente de uma série de estudos produzidos por instituições governamentais e pesquisadores, principalmente sobre a bacia do Ipojuca, para assim compor a primeira etapa do diagnóstico por meio da caracterização ambiental física. Em seguida, através de entrevistas in loco, buscou-se identificar os atores sociais, residentes e temporários para obter uma noção dos diferentes graus de relação com o riacho.

\section{RESULTADOS E DISCUSSÃO}

O caráter preventivo que se objetivou dar a esta pesquisa tem como ponto de partida a análise dos impactos que são processados diariamente pela densidade populacional à dinâmica hidrográfica do riacho do Mel. O levantamento de uso e ocupação do solo traz um quadro inicial para discorremos sobre o assunto.

\footnotetext{
A identificação da ocupação (elementos naturais) e uso (elementos das atividades Humanas) do solo, constitui-se em importantíssimo elemento num estudo ligado à temática ambiental, pois, o mais atualizado sobre uma determinada localidade auxiliará, dentre outros, a identificar e localizar os agentes responsáveis pelas condições ambientais da área. (MENDONÇA, 1999, p. 77)
}

Ao longo da pesquisa, foram encontrados diferentes tipos de uso (Figura 1). A partir da sua foz, a atividade industrial é representada por uma empresa do setor de laticínios. Para esta, contamos o primeiro barramento feito dentro da área estudada, voltado para o uso da empresa e irrigação de capim, atividade agrícola que se repetirá, associada a áreas de pasto e à criação extensiva de bovinos, nas áreas subsequentes onde este tipo de imóvel aparece dentro do espaço representado.

Foram encontrados três tipos de imóveis residenciais, os que já estão consolidados fazem parte de um bairro com população de baixa renda e com escasso aparato urbano, gerando um contraste notável. Há um condomínio de alto padrão e entre ambos, o loteamento Riacho do Mel ainda em vias 
de ocupação. Nota-se que o uso abusivo dos recursos naturais em detrimento de um padrão estético para moradias, fato corriqueiro na região, sem qualquer benefício para a sociedade ou mesmo para os habitantes locais, configura-se como mais um dos agravos gerados pelas posturas controversas das ações humanas.

Figura 1: Mapa de uso e ocupação da terra.

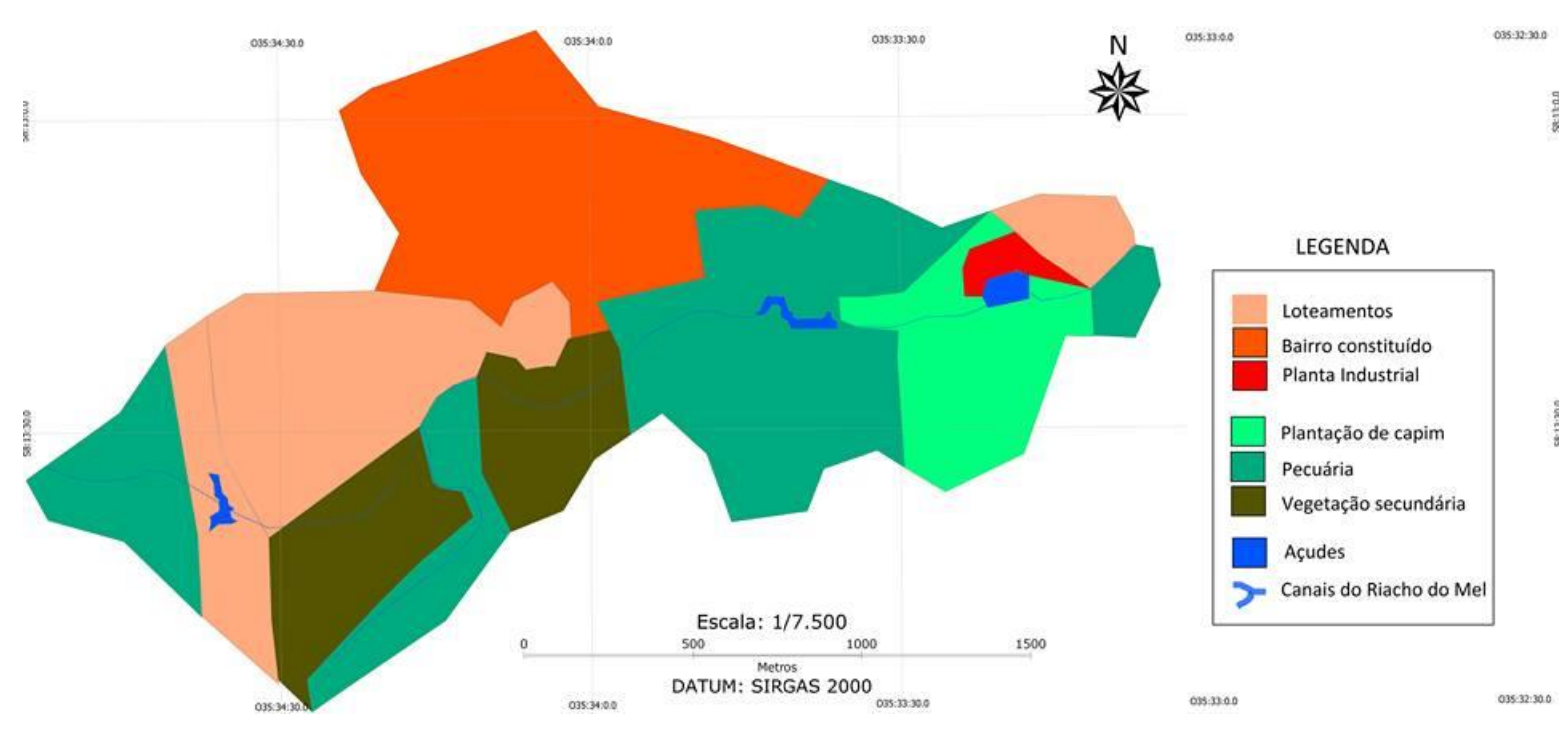

Organização: Diogo Cavalcanti (2014).

No tocante à área de vegetação secundária, não fazendo parte de qualquer propriedade privada, representa também áreas da calha do riacho onde a velocidade do fluxo era mais intensa e abundante outrora, sendo assim, terras não exploradas para qualquer atividade econômica. Portanto, há ainda espaços "naturais" a serem conservados, para tal, o estado deve fazer valer a aplicação da legislação ambiental.

A partir da análise do uso da terra, podemos perceber que as atividades geram impactos de diferentes níveis (Figura 2); devido à área em questão ainda ser limítrofe do perímetro urbano, a atividade agrícola é predominante no uso da água existente. Destacamos os sucessivos barramentos do curso do riacho como condição para a atual situação de escassez de fluxo no corpo hídrico. Há também fatores naturais que agravam tal situação. Como foi aferido através de entrevistas, segundo declaração de fazendeiros locais, no ano de 2013, não ocorreu nenhuma cheia ou aumento considerável no nível do Riacho do Mel. Essa informação foi comprovada em nosso registro de campo, bem como por dados de monitoramento da APAC - Agência Pernambucana de Águas e Clima, segundo a qual, no ano de 2013, em os registros mensais ficaram abaixo da média estimada para a região ${ }^{5}$.

5 Informação disponível em: http://www.apac.pe.gov.br/meteorologia/monitoramento-pluvio.php. 
Figura 2: Impactos ambientais.

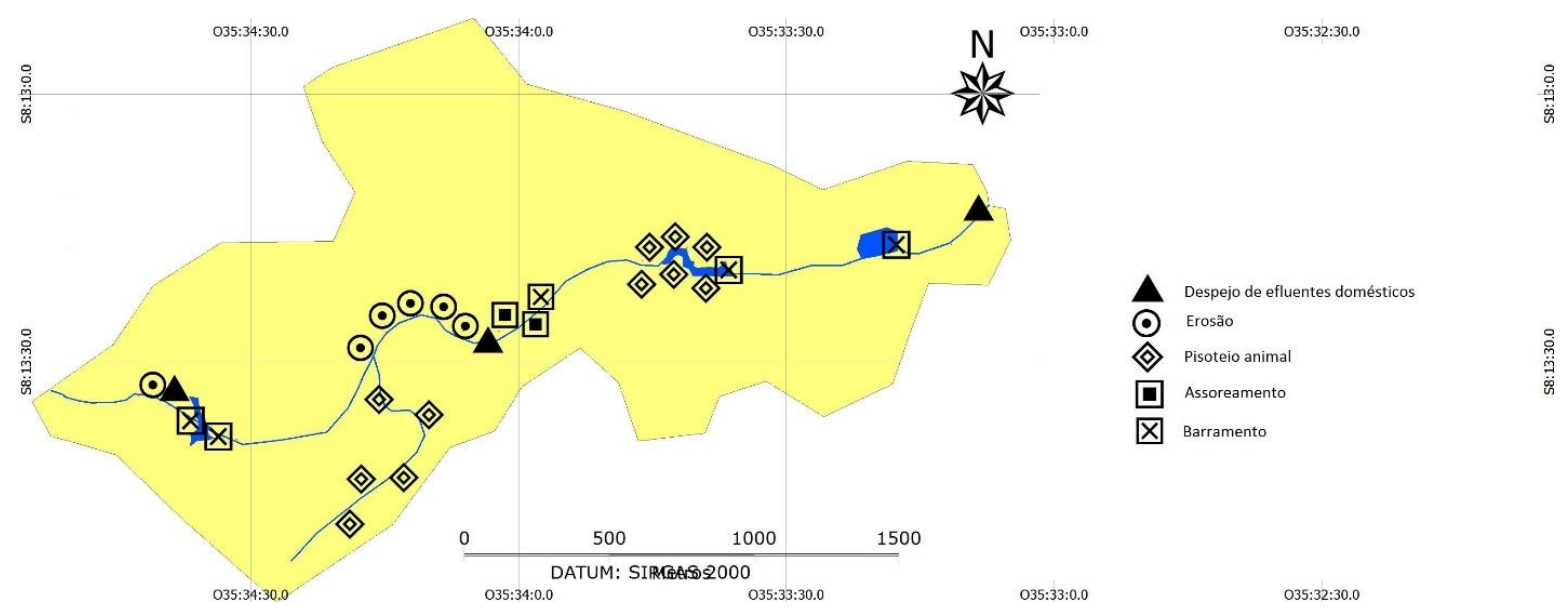

Organização: Diogo Cavalcanti (2014).

O impacto dos barramentos geralmente está ligado a atividades que se desenvolvem com uso da água estancada. No caso dos dois primeiros barramentos, a criação de bovinos gera a compactação do solo. Temos, nas palavras de Marchão et al. (2009, p.2), um panorama que condiz com o observado em campo,

A compactação do solo pelo pisoteio animal, agravada pela remoção da vegetação pelo pastoreio pode diminuir a taxa de infiltração, aumentar a erosão e reduzir o crescimento radicular das plantas. Como consequência do superpastejo sobre a pastagem, tem-se uma perda da cobertura de solo que, devido ao impacto do pisoteio excessivo sob altas taxas de lotação, pode provocar compactação. É importante ressaltar que essa compactação depende, principalmente, da classe de solo, do seu teor de umidade, da taxa de lotação animal, da massa de forragem e da espécie forrageira utilizada no sistema.

Este tipo de impacto afeta mais a vertente à direita, uma vez que se trata de uma área comumente inundada em períodos de cheias devido à velocidade do escoamento e a pouca capacidade de captação. 0 proprietário do imóvel afirmou ter ficado ilhado esperando o nível da água baixar durante anos de precipitação acima da média.

Vale salientar que este ponto de inundação é contíguo ao terceiro e quarto barramentos, chamando particular atenção o fato de estes terem sido feitos para abrigar um condomínio de alto padrão. No lado que recebe o fluxo, o canal foi alterado em largura e profundidade, além de ter tido as margens cimentadas para evitar erosão, ou seja, construiu-se um reservatório controlado por válvula, que limitará consideravelmente uma parte do fluxo e é utilizado para alimentar um lago artificial dentro do citado condomínio. Anexo a este, porém fora de seus muros, há uma obra de proporções bastante consideráveis que, apesar de inacabada já provocou alterações notáveis (Figura 3), apesar de ainda existirem impactos por analisar. A Resolução do CONAMA Nº 001 de 1986, deixa clara amplitude dos impactos a considerar, quando referenda: 
Artigo $1^{\text {o }}$ - Para efeito desta Resolução, considera-se impacto ambiental qualquer alteração das propriedades físicas, químicas e biológicas do meio ambiente, causada por qualquer forma de matéria ou energia resultante das atividades humanas que, direta ou indiretamente, afetam:

I - a saúde, a segurança e o bem-estar da população;

II - as atividades sociais e econômicas;

III - a biota;

IV - as condições estéticas e sanitárias do meio ambiente;

$\mathrm{V}$ - a qualidade dos recursos ambientais.

(IBAMA, 1986)

Figura 3: Obra de alteração do canal do Riacho do Mel, próxima a um condomínio de alto padrão.

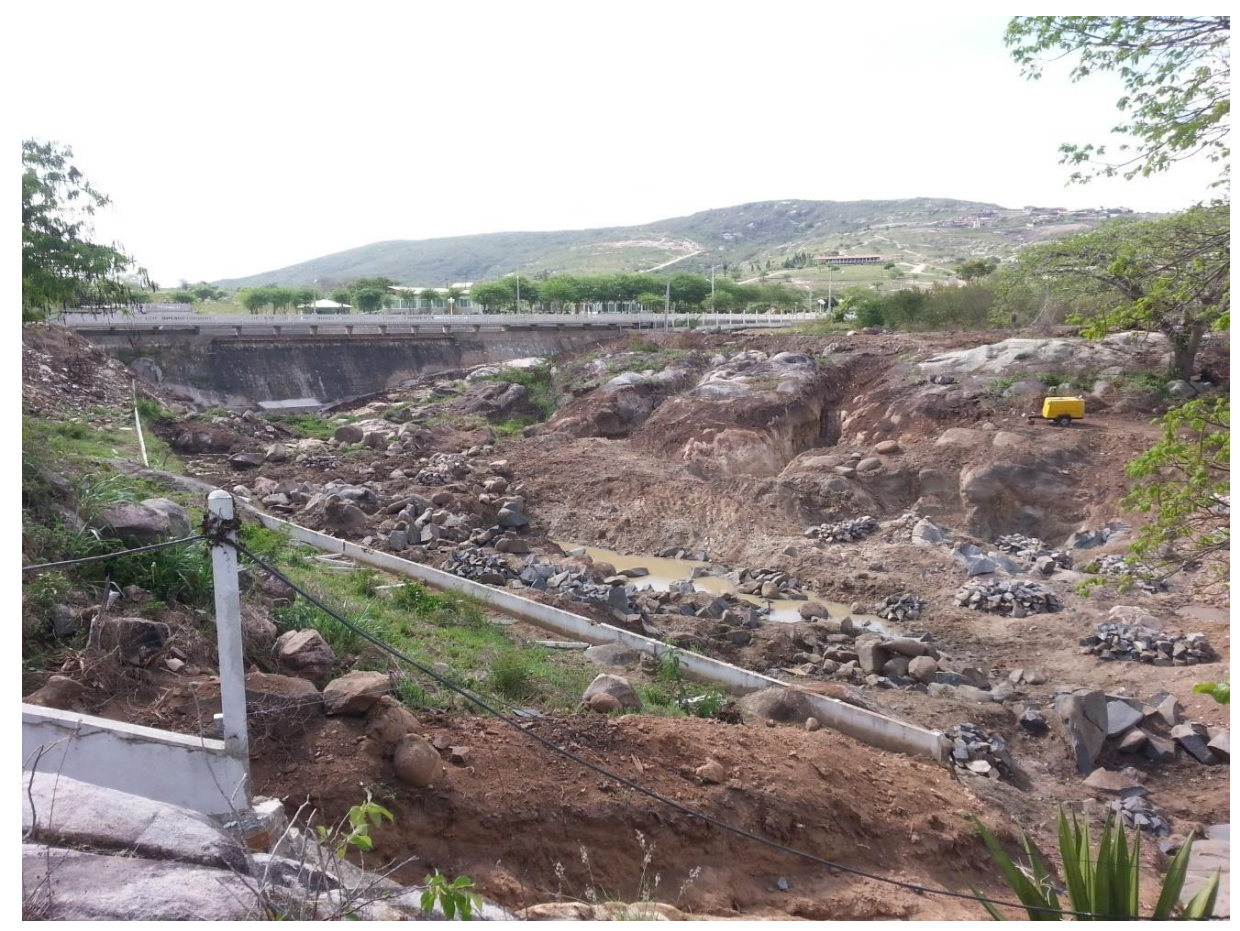

Autor: Kleython Monteiro, em 12/01/14.

Ao fluxo estacionário, o acesso à água exclusivo e pontual, soma-se o despejo de efluentes sem qualquer tipo de tratamento, oriundo de uma população crescente que habita um bairro com escasso aparato urbano resultando na formação de acúmulos de esgoto como o que foi observado próximo ao loteamento, tornando-se um verdadeiro afluente de dejetos constante do Riacho do Mel. Além deste já existente, que não pode ser escoado diretamente no rio Ipojuca, fica a inquietação de como serão manejados os efluentes gerados pela ocupação dos novos 866 lotes do empreendimento.

Levando-se em consideração o grau de declividade onde estão localizados os loteamentos (Figura 4) e sua ocupação esparsa, já é possível observar consequências, devido a alteração na rede de drenagem, as principais avenidas se encontram com sinais de erosão, expressos por caminhos escavados pela água da chuva em sua vertente até o leito. 
Figura 4: Mapa Hipsométrico e perfis topográficos.

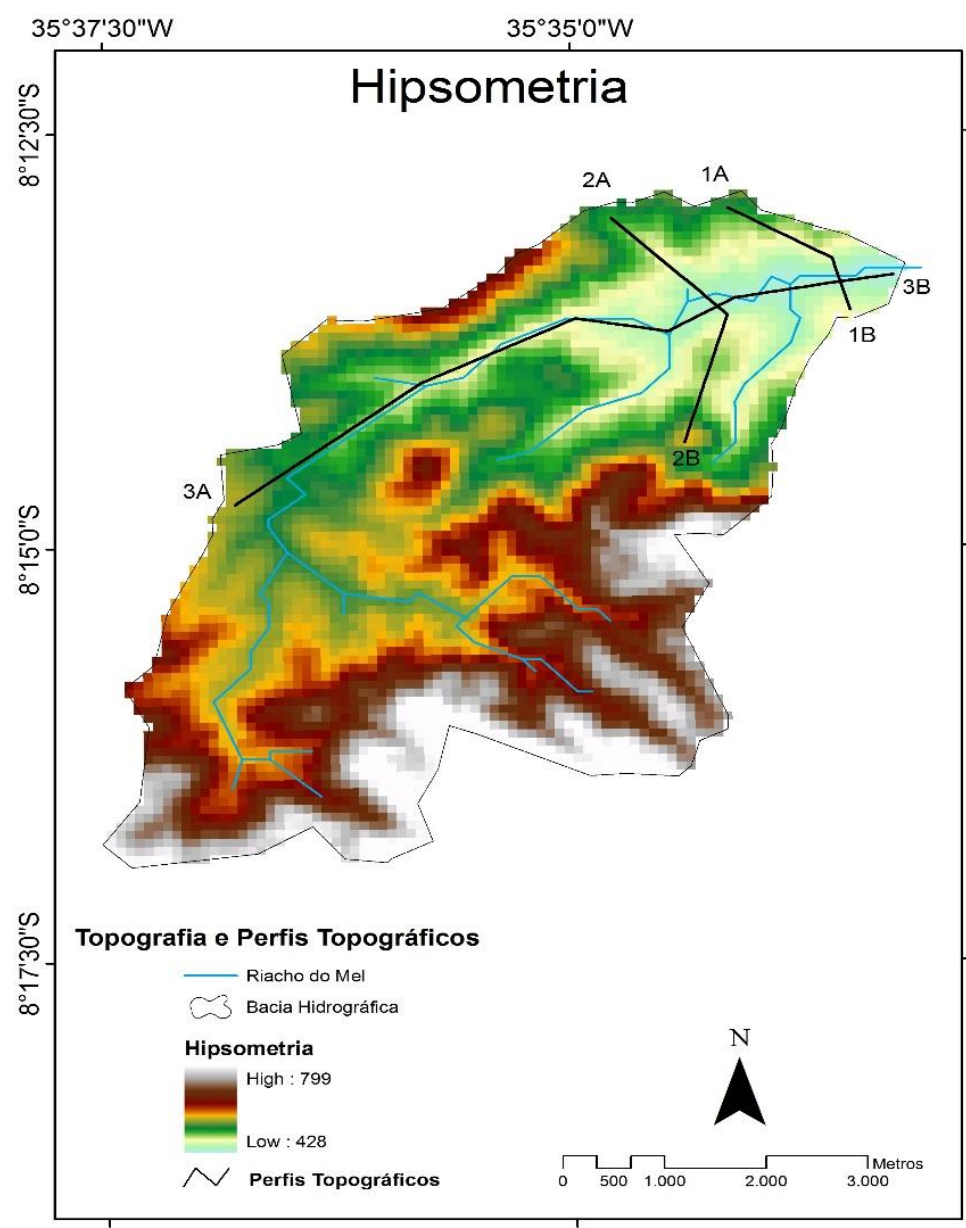

Organização: Diogo Cavalcanti (2014)

Com o esperado aumento da impermeabilização, os processos supracitados tendem a se agravar em intensidade, tanto no que diz respeito ao fluxo quanto à velocidade do escoamento. 0 consequente carreamento de material pode vir a ocasionar um futuro ponto de alagamento quando a precipitação for mais intensa. 0 quadro atual de infraestrutura para escoamento de águas pluviais é de um ponto para drenagem do fluxo, obra que é importante, mas, claramente insuficiente, haja vista a série de canais já erodidos em diferentes pontos do bairro.

Como último ponto, tem-se um apurado dos dados fornecidos pela Prefeitura, na busca de traçar um perfil socioeconômico da população que reside no bairro Riacho Mel, estabelecendo-se correlações entre os usos da terra e as dinâmicas populacionais.

No total, foram 411 entrevistados desde 2013 até 2017. Destes, 295 afirmaram participar do programa Bolsa Família do Governo Federal. Um dos critérios para receber este auxílio, segundo site da Caixa Econômica, é ter renda familiar per capita de até $\mathrm{R} \$ 85,00$, situação que foi comprovada em campo, 294 entrevistados se enquadram nessa faixa, 36 estão entre $R \$ 85,01$ e $R \$ 170,00,62$ entrevistados estão entre $\mathrm{R} \$ 170,00$ e 1/2 salário-mínimo e por último acima deste valor se acham 19 
famílias. Os dados econômicos são um importante sinal para a percepção da realidade dos moradores da região, mas ao relacioná-los com dados sobre a infraestrutura tanto das habitações quanto do bairro, ampliam-se e definem-se melhor certas especificidades observadas.

Traremos aqui duas características que estão diretamente relacionadas à saúde ambiental, a coleta de lixo e o escoamento sanitário. Tratando-se da coleta, 367 pessoas afirmaram que os resíduos são coletados diretamente, ou seja, são atendidos pelo sistema de coleta urbana, 24 afirmaram que tem seu lixo coletado indiretamente, 13 queimam ou enterram e 2 destinam seu lixo a terreno baldio ou logradouro. No que diz respeito ao escoamento dos efluentes domésticos, 339 imóveis escoam pela rede coletora de esgoto ou pluvial, 41 utilizam fossa rudimentar, 15, vala a céu aberto e 1 entrevistado utiliza outra forma de escoamento, um detalhe importante é que em 12 casos, ainda não havia banheiro no imóvel.

Dessa forma, é possível constatar que os habitantes do bairro riacho do Mel pertencem majoritariamente a famílias com baixo poder aquisitivo e, apesar dos dados dentre a população pesquisada, demonstrarem uma boa cobertura quanto à coleta de lixo e escoamento sanitário, observam-se muitas moradias carentes de infraestrutura básica.

Diante do exposto, urge um controle do uso do ambiente na medida em que, boa parte dos impactos que foram constatados, ocorre por desinformação, por falta de fiscalização e desrespeito ao meio ambiente. Não só no que se refere à natureza, mas também no tocante à gestão da expansão urbana, pois ambos estão imbricados.

\section{CONSIDERAÇõES FINAIS}

Acredita-se que ao explicitar os principais fluxos de energia e matéria, bem como suas fontes no claro dinamismo territorial provocado na microbacia do riacho do Mel, mostrou-se o quadro de riscos ambientais em função do processo de uso ocupação, objetivo principal deste estudo. Entretanto, destaca-se que esse é somente o passo inicial na tentativa de compreender a atual configuração desta paisagem e também das possíveis consequências que tais modificações podem vir a acarretar.

A infeliz constatação de que o sistema hídrico riacho do Mel foi, e é manipulado sem qualquer tipo de consideração aos parâmetros ambientais, leva-nos a supor um futuro de prejuízos para a dinâmica natural da área. Levando em consideração o gradual aumento populacional urbana em torno desta bacia, e analisando as situações dos riachos e dos córregos em estágios mais avançados de degradação, urge uma proposta de zoneamento ambiental como uma primeira alternativa a proteção dos recursos ambientais ainda existentes. Regulamentado pela Lei 6.938 de 1981, que dispõe sobre a PNMA o zoneamento ambiental deverá contemplar: 
1 - a caracterização ambiental da área, constando: o potencial ambiental; os efeitos das atividades agrárias, urbanas, industriais e de infra-estrutura e o estado de preservação do meio ambiente natural; os riscos ambientais e sociais; a avaliação do grau de sustentabilidade e vulnerabilidade dos sistemas ambientais;

2 - a indicação de medidas de controle ou minimização dos efeitos da ocupação e da exploração dos recursos naturais, e de restrições de uso;

3 - a indicação de alternativas de desenvolvimento compatíveis com a sustentabilidade e a vulnerabilidade dos sistemas ambientais;

4 - o prognóstico das alternativas de uso;

5 - a indicação das atividades já existentes na área que, por incompatibilidade com o zoneamento, deverão ser realocadas ou compensadas.

E este zoneamento, deve ocorrer em consonância com o plano diretor participativo municipal, orientando as ações em busca do desenvolvimento observado na cidade como um todo. A cidade de Gravatá possui seu plano diretor desde 2006, como resultado de um extenso levantamento pelo IPAD Instituto de Planejamento e Apoio ao Desenvolvimento tecnológico e científico, resultando num texto base que aborda vários pontos relevantes para o desenvolvimento urbano, dentre os quais se destaca o ambiental (IPAD, 2006).

Neste documento, observa-se grande preocupação no que diz respeito às questões ambientais, inclusive propondo a criação do SISMUC - Sistema Municipal de Unidade de Conservação, sendo este o principal instrumento de preservação ambiental do município, além da implementação do Sistema Municipal de Informações Urbanas Ambientais - SUA e do Licenciamento Ambiental, todos como estratégia para atingir o mítico desenvolvimento com respeito ao meio ambiente.

Porém, colocamos em questão a ausência de proposições a respeito das sub-bacias do rio Ipojuca, para justificar a necessidade de uma mudança na visão da gestão territorial. Isso porque a escala de ação/observação proporcionada pela gestão de microbacias explicita com fidedignidade a realidade local, seus usos e consequências, é também nesta escala que se pode minimizar alguns impactos nos cursos principais.

São propostos diferentes zoneamentos que envolvem a Bacia do Rio Ipojuca, classificando-a em áreas de zoneamento rural, no caso a Zona Rural Bacia Hidrográfica do Ipojuca - ZRI, que "Constitui a área do território municipal pertencente à Bacia Hidrográfica do Rio Ipojuca, excluindo-se a área urbana." Quanto a Zona Especial de Interesse Agroecológico - ZEIA, esta é descrita da seguinte maneira: "O Zoneamento Especial tem a finalidade de regular o uso e a ocupação do solo, com vistas à integração entre o desenvolvimento econômico e a necessidade de conservação do patrimônio natural, construído.". 
Braga (2009) cita Dorigon que, através de sua fala, nos dá uma importante noção sobre a escala de análise permitida por uma microbacia,

Ela é (microbacia) a menor unidade territorial capaz de enfocar as variáveis ambientais de forma sistemática, sob o aspecto da gestão. Em consequência a solução dos problemas identificados está ao nível da população local, o que contribui para um gerenciamento mais adequado dos recursos naturais e dos conflitos de uso. (DORIGON apud BRAGA, 2009, p. 24)

Enfim, como se sabe, é notória a distância que existe entre o que propõe a Legislação Ambiental Brasileira e a sua aplicação na prática, o que também não é diferente com respeito ao Plano Diretor. Porém, não devem diminuir as tentativas em buscar concretizar o que está na legislação existente. Não fazer qualquer menção às sub-bacias dos principais rios que cortam o território do município, referindo-se a eles apenas como afluentes, explicita uma visão e tentativa equivocadas de manejo de bacias hidrográficas, pois desconsideram uma série de elementos que fazem parte e influenciam diretamente os principais corpos d'água. Em decorrência deste tipo de visão limitada, os problemas, no que se refere principalmente a catástrofes urbanas, têm sido tratados quando já não há muito que ser feito sem o envolvimento de vultosas quantias de dinheiro, inviabilizando possíveis soluções para questões que poderiam ser evitadas nas etapas de planejamento e fiscalização urbana e ambiental.

\section{REFERÊNCIAS}

BRAGA, R. Instrumentos para a gestão ambiental e de recursos hídricos. Ed Universitária da UFPE, 2009.134p.

BRASIL. Lei $n^{\circ}$. 6.938 de 31 de agosto de 1981. Dispõe sobre a Política Nacional do Meio Ambiente, seus fins e mecanismos de formulação e aplicação, e dá outras providências. Diário Oficial da República Federativa do Brasil, Brasília, DF, 2 de setembro de 1981. Disponível em: http://www.planalto.gov.br/ccivil_03/leis/ L6938.htm . Acesso em: 13.01.2014.

CARLOS, A. F. A. O lugar no/do mundo. São Paulo: FFLCH, 2007, 85p.

COELHO, M. C. N. Impactos Ambientais em Áreas Urbanas: Teorias, Conceitos e Métodos de Pesquisa. In GUERRA, Antonio Teixeira. CUNHA, Sandra Baptista da. (Orgs.). Impactos Ambientais Urbanos no Brasil. Rio de Janeiro: Bretand Brasil, 2010. CUNHA, S. B. Canais Fluviais e a questão ambiental. In: CUNHA, S. B.; GUERRA, A. J. T. (orgs.). A questão Ambiental: diferentes abordagens. Ed. Betrand Brasil, Rio de Janeiro, 5.ed., 2010. pp. 219 - 235.

INSTITUTO BRASILEIRO DE GEOGRAFIA E ESTATISTICA. Censo Demográfico 2010. Disponível em: http://www.censo2010.ibge.gov.br Acesso em: 20 de Ago. 2013.

CONSELHO NACIONAL DO MEIO AMBIENTE CONAMA. Resolução no 01, de 23 de janeiro de 1986. Dispõe sobre critérios básicos e diretrizes gerais para o Relatório de Impacto Ambiental - RIMA. Disponível em: http://www.mma.gov.br/port/conama/legi abre.cfm codlegi=23.Acesso em: 04 mai. 2013.

IPAD - INSTITUTO DE PLANEJAMENTO E APOIO AO DESENVOLVIMENTO TECNOLÓGICO E CIENTÍFICO. Plano diretor participativo Gravatá - PE. Recife, 2006.

JACOMINE, P. K. T. Nova Classificação Brasileira de Solos. Anais da Academia Pernambucana de Ciência Agronômica. Recife, Pernambuco. v. 5 e 6, p. 161 - 179, 2008 - 2009. 
MARCHÃO, R. L., VILELA, L., PALUDO, A. L. GUIMARÃES JUNIOR, R. Impacto do Pisoteio Animal na Compactação do solo sob a Integração da Lavoura - Pecuária no Oeste Baiano. Planaltina, DF: Embrapa Cerrados, 2009, 6 p. Embrapa Cerrados. Comunicado Técnico, n. 163.

MENDONÇA, F. A. Diagnóstico e análise ambiental de microbacia hidrográfica: proposição metodológica na perspectiva do zoneamento, planejamento e gestão ambiental. RAEGA: O espaço geográfico em análise. v.3 n.3 Curitiba: Editora da UFPR, 1999.

SÁNCHEZ, L. H. Avaliação de impacto ambiental: conceitos e métodos. São Paulo, Oficina de textos, 2 ed. 2013.

VASCONCELLOS, M. J. E. Pensamento sistêmico: 0 novo paradigma da ciência. Campinas, SP: Papirus,2002. p.268.

VIANA RODRIGUES, M. C. Desenvolvimento local, Turismo e lazer no agreste central de Pernambuco. 2007. 204 f. Tese (Doutorado em Ciências Sociais). Instituto de Ciências Sociais, Universidade Federal Rural do Rio de Janeiro, Rio de Janeiro. 2007.

ZAPPI, D. Fitofisionomia da caatinga associada à cadeia do Espinhaço. Revista Megadiversidade. Belo Horizonte, Minas Gerais. vol. 4, no1-2, p. 34-38, 2008. 